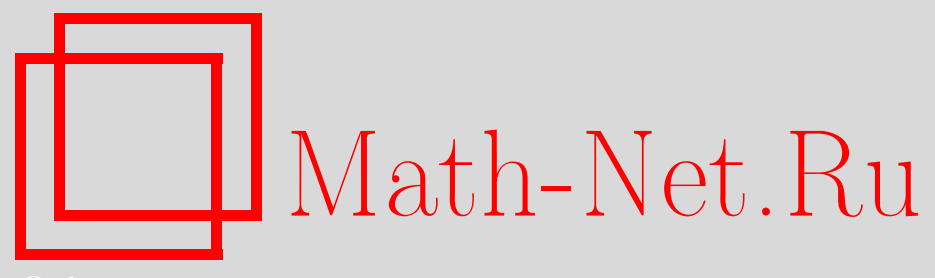

Е. Соколов, Эгоцентризм, системы мира и воздушный шарик, Квант, 2021, номер 4, 2-4

DOI: https://doi.org/10.4213/kvant20210401

Использование Общероссийского математического портала Math-Net.Ru подразумевает, что вы прочитали и согласны с пользовательским соглашением http://www.mathnet.ru/rus/agreement

Параметры загрузки:

IP : 54.147 .182 .235

26 апреля 2023 г., 18:28:47

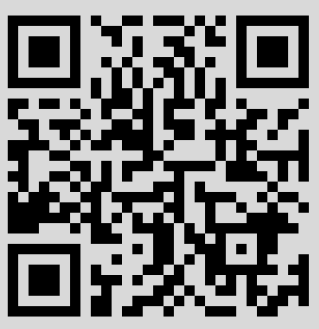




\section{Эгоцентризм, системы мира и воздушный шарик}

\section{Е.СОКОЛОВ}

Две вещи наполняют душу мою вечно новым и все возрастающим удивлением и благоговением... - это звездное небо надо мною и нравственный закон во мне.

\section{Иммануил Кант. Критика практического разума}

\section{1} ЕБЕНОК ВСЕГДА РАСПОЛАГАЕТ себя в центре Мира. Он считает, что все вокруг совершается для него и ради него. Такое отношение к Миру называется эгоцентризмом (от лат. ego - я и centrum центр). Бывает, что и взрослые люди не могут избавиться от эгоцентризма. Тогда это приводит их к проблемам в общении.

Три тысячи лет назад молодое человечество поступило так же, как поступают

DOI: https://doi.org/10.4213/kvant20210401 дети. Оно поместило нашу планету Земля в центр Вселенной. Такая система мира получила название геоцентрической (от

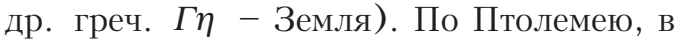
центре такой системы находится Земля (рис.1). Ее окружают восемь хрустальных сфер, на которых располагаются небесные тела. А что за ними? На этот счет существовали различные мнения: другие миры (Демокрит), двигатель (Аристотель), ничто (стоики), сфера ангелов (теологи).

B XVI веке Николай Коперник предложил гелиоцентрическую систему мира (от

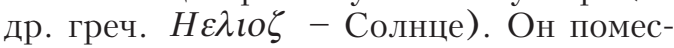
тил в центр Вселенной нашу звезду Солнце (рис.2). Земля и Солнце поменялись местами, но суть осталась прежней центром Вселенной осталась наша Солнечная система.

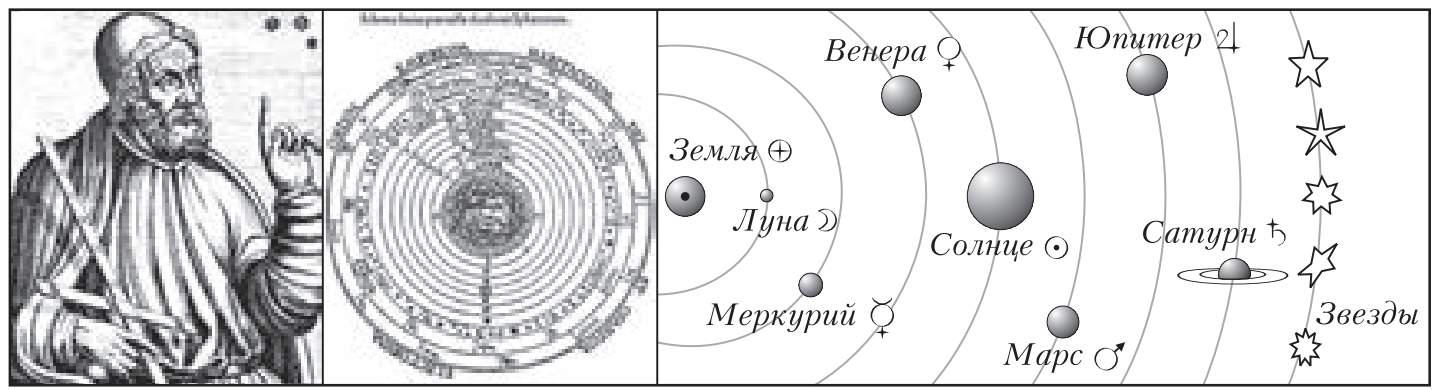

Рис. 1. Геоцентрическая система мира по Птолемею

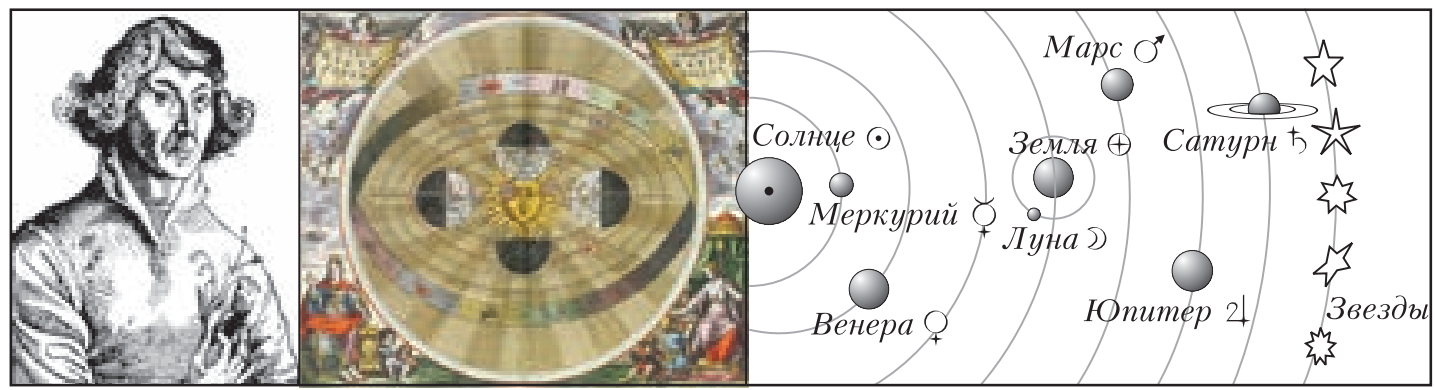

Рис. 2. Гелиоцентрическая система Коперника 


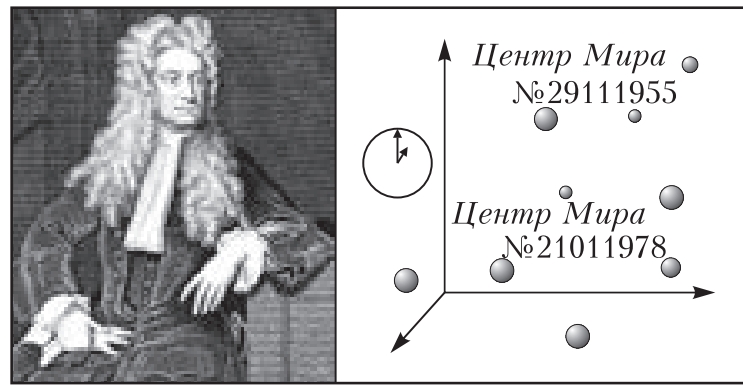

a)

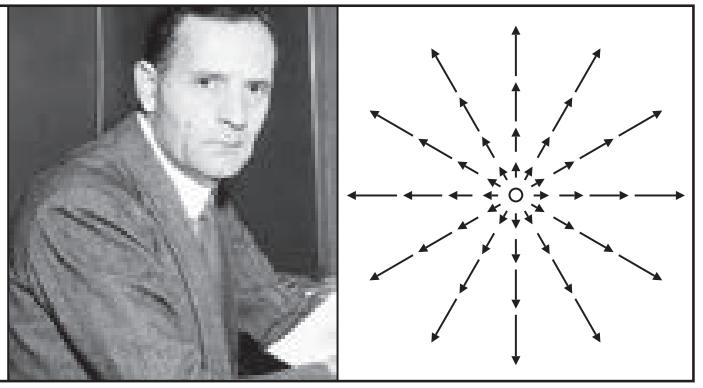

б)

Рис. 3. а) "Демократическая» Вселенная Ньютона;

Человечество повзрослело благодаря Исааку Ньютону. По Ньютону, Вселенная есть бесконечное неизменное абсолютное пространство, в котором равномерно и неумолимо течет абсолютное время. А что касается центра Вселенной, то, согласно Ньютону, наша Вселенная абсолютно демократична - любое тело может быть выбрано в качестве центра Вселенной (рис.3, $a)$.

Абсолютное спокойствие ньютоновской картины Мира было нарушено, когда в 1929 году американский астроном Эдвин Хаббл обнаружил, что все галактики (громадные звездные скопления) разбегаются от нас во все стороны. При этом скорость их удаления оказалась прямо пропорциональной расстоянию до них:

$$
v=H \cdot R,
$$

где $H=2,2 \cdot 10^{-18} 1 / \mathrm{c}-$ постоянная Хаббла, которую он определил из своих наблюдений.

Посмотрите на рисунок 3,б, который иллюстрирует закон Хаббла. Что из него видно? Что наша Вселенная имеет центр!
И этот центр - мы! Это настолько очевидно, что сразу же после открытия Хаббла газеты запестрели заголовками: «Настоящий центр Вселенной - наша галактика Млечный Путь!», «Мы - центр Вселенной!», «Мы - ...! , «Мы - ..!» и только «Мы $-\ldots$ !»

Картинка на рисунке 3,б - сама очевидность, но доказывает ли она на самом деле, что наша Галактика является центром Вселенной? Не будем спешить с ответом и разберем следующую ситуацию:

Астрономы планеты А видят, что все остальные планеты разлетаются от нее в разные стороны (рис.4,a). При этом скорость удаления каждой планеты прямо пропорииональна расстоянию до нее. Что видят астрономы планеты В?

Слова о том, что планеты разлетаются в разные стороны со скоростями, прямо пропорциональными расстоянию до них, означают, что скорость всех разлетающихся планет подчиняется закону $\vec{v}=H \cdot \vec{R}$, где $\vec{R}$ - радиус-вектор некоторой планеты относительно планеты $A$, а $H$ - некоторый постоянный для всех планет коэффици-

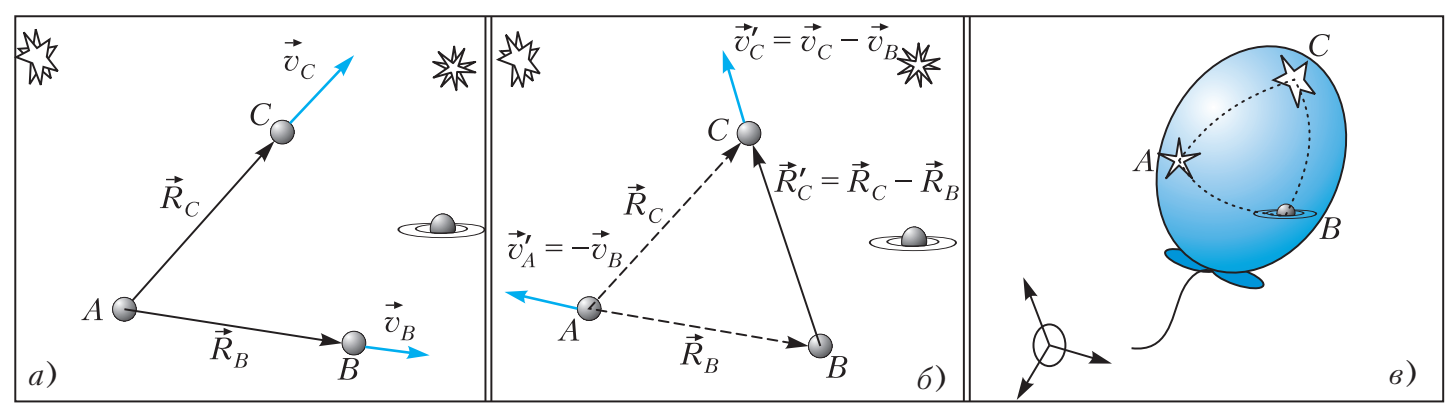

Рис. 4. а) и б) Разлетающиеся планеты; в) наша Вселенная как летящий воздушный шарик 
ент. Отсюда для скоростей двух произвольных планет $B$ и $C$ получаем

$$
\vec{v}_{B}=H \cdot \vec{R}_{B} \text { и } \vec{v}_{C}=H \cdot \vec{R}_{C} .
$$

Чтобы узнать, что видят астрономы планеты $B$, сядем на эту планету. В новой системе отсчета (системе отсчета, связанной с планетой $B$ ) мы, конечно, увидим все те же тела, но вот скорости у них будут другие. Согласно классическому закону сложения скоростей, при переходе в систему отсчета, движущуюся со скоростью $\vec{v}_{B}$, скорости всех других тел, следует пересчитать по правилу

$$
\vec{v}^{\prime}=\vec{v}-\vec{v}_{B}
$$

Поэтому скорость планеты $C$ в системе отсчета, связанной с планетой $B$ (рис.4,б), будет равна

$$
\begin{aligned}
\vec{v}_{C}^{\prime}=\vec{v}_{C}-\vec{v}_{B}=H & \cdot \vec{R}_{C}-H \cdot \vec{R}_{B}= \\
& =H \cdot\left(\vec{R}_{C}-\vec{R}_{B}\right)=H \cdot \vec{R}_{C}^{\prime} .
\end{aligned}
$$

Осталось прочитать этот ответ: астрономы планеты $B$ видят... то же самое, что и астрономы планеты $A,-$ все планеты разлетаются от них в разные стороны со скоростями, прямо пропорциональными удаленности планеты. Иными словами, астрономы любой планеты видят одно и то же, абсолютная демократичность нашей Вселенной спасена!

Открытый Э.Хабблом факт разлета галактик было первым подтверждением те- ории Большого взрыва. Согласно этой теории когда-то, давным-давно, наша Вселенная была просто точкой, а потом стала безостановочно расширяться. Закон Хаббла позволяет определить, когда это произошло. Для этого достаточно просто разделить расстояние, которое успела пролететь каждая галактика, на ее скорость:

$$
\begin{aligned}
T=\frac{R}{v}=\frac{R}{H \cdot R}=\frac{1}{H}=4,5 \cdot 10^{17} \mathrm{c}= \\
=14 \text { млрд лет. }
\end{aligned}
$$

Итак, вот уже четырнадцать миллиардов лет существует наша Вселенная. В ней бушуют космические бури, образуются черные дыры, рождаются и умирают звезды. Но что самое интересное, в ней до сих пор существуют непосредственные свидетели того неимоверно далекого события - рождения нашей Вселенной! Кто они? Это частицы света, которые были рождены в момент Большого взрыва, реликтовое излучение. Четырнадцать миллиардов лет они движутся без остановок и хранят в себе историю самых первых моментов жизни нашей Вселенной. Ученые пытливо изучают их (рис.5). Они пытаются прочитать в этих частицах тайны нашей Вселенной.

Недавно было выяснено, что «тонкие детали распределения реликтового излучения по направлениям», возможно, указывают на то, что все-таки центр у нашей

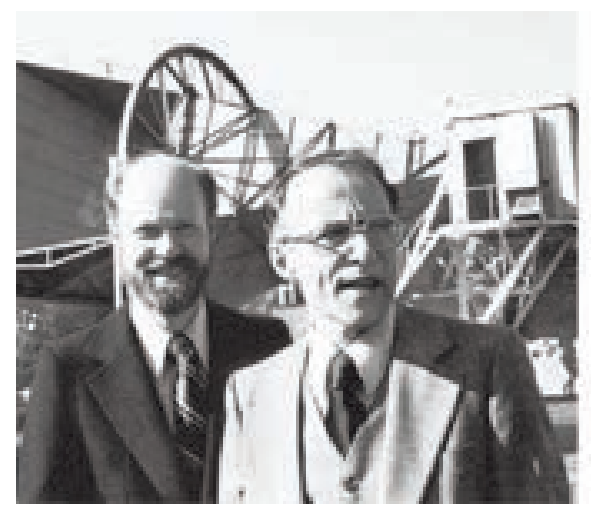

a)
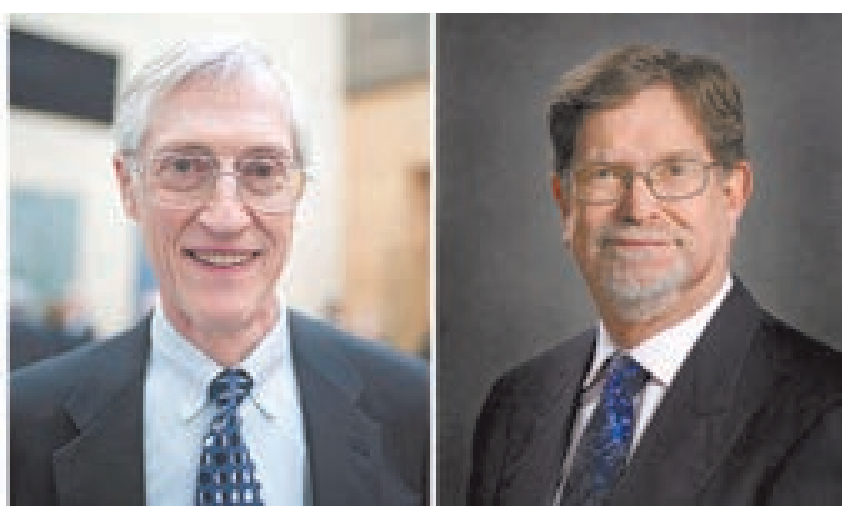

б)

Рис. 5. а) Р.Вильсон и А.Пензиас - лауреаты Нобелевской премии 1978 года за открытие реликтового излучения; б) Д.Мазер и Д.Смут - лауреаты Нобелевской премии 2006 года за изучение свойств реликтового излучения 